\title{
Association Between the Communication Skills of Physicians and the Signing of Do-Not-Resuscitate Consent for Terminally III Patients in Emergency Rooms (Cross-Sectional Study)
}

This article was published in the following Dove Press journal:

Risk Management and Healthcare Policy

Chih-Hung Chen, ${ }^{1,2, *}$ Ya-Hui Cheng, ${ }^{3,4, *}$ Fen-Ju Chen, ${ }^{5}$ EngYen Huang, ${ }^{6}$ Po-Ming Liu, ${ }^{7}$ Chia-Te Kung, ${ }^{8}$ Chao-Hui Su, ${ }^{3}$ Shu-Hwa Chen, ${ }^{3,9}$ Peng-Chen Chien, ${ }^{10}$ Ching-Hua Hsieh (D) 10

'Department of Internal Medicine, Kaohsiung Chang Gung Memorial Hospital and Chang

Gung University College of Medicine,

Kaohsiung 833, Taiwan; ${ }^{2}$ Graduate Institute of Adult Education, National Kaohsiung Normal University, Kaohsiung 802, Taiwan;

${ }^{3}$ Department of Nursing, Kaohsiung Chang Gung Memorial Hospital and Chang Gung University College of Medicine, Kaohsiung 833, Taiwan; ${ }^{4}$ Department of Nursing, MinHwei Junior College of Health Care Management, Tainan, 736, Taiwan;

${ }^{5}$ Department of Healthcare Administration, I-Shou University Medical Campus, Kaohsiung 824, Taiwan; ${ }^{6}$ Department of Radiation Oncology, Kaohsiung Chang Gung Memorial Hospital and Chang Gung University College of Medicine, Kaohsiung 833, Taiwan;

${ }^{7}$ Department of Emergency Medicine, Kaohsiung 802, Taiwan; ${ }^{8}$ Department of Emergency Medicine, Kaohsiung Chang Gung Memorial Hospital and Chang Gung University College of Medicine, Kaohsiung 833, Taiwan; ${ }^{9}$ School of Nursing, Fooyin University, Kaohsiung 83I, Taiwan; ${ }^{10}$ Department of Plastic Surgery, Kaohsiung Chang Gung Memorial Hospital and Chang Gung University College of Medicine, Kaohsiung 833, Taiwan

*These authors contributed equally to this work

Correspondence: Ching-Hua Hsieh Department of Plastic Surgery, Kaohsiung Chang Gung Memorial Hospital and Chang Gung University College of Medicine, No. 123, Ta-Pei Road, NiaoSong District, Kaohsiung City 833, Taiwan Emailm93chinghua@gmail.com
Background: The signing of do-not-resuscitate (DNR) consent is mandatory in providing a palliative approach in the end-of-life care for the terminally ill patients and requires an effective communication between the physician and the patients or their family members. This study aimed to investigate the association between the communication skills of physicians who participated in the SHARE (supportive environment, how to deliver the bad news, additional information, reassurance, and emotional support) model course on the patient notification and the signing of do-not-resuscitate (DNR) consent by the terminally ill patients at emergency rooms.

Methods: Between May 1, 2017 and April 30, 2018, a total of 109 terminally ill patients were enrolled in this study, of which 70 had signed a DNR and 39 had not. Data regarding the patients' medical records, a questionnaire survey completed by family members, and patient observation forms were used for the assessment of physicians' communication skills during patient notification. The observation form was designed based on the SHARE model. A multivariate logistic regression model was applied to identify the independent significant factors of the patient and family member variables as well as the four main components of the observation form

Results: The results revealed that knowing how to convey bad news and providing reassurance and emotional support were significantly correlated with a higher rate of signing DNR consent. Additionally, physician-initiated discussion with family members and a predicted limited life expectancy were negative independent significant factors for signing DNR consent.

Conclusion: This study revealed that good communication skills help to increase the signing of DNR consent. The learning of such skills from attendance of the SHARE model course is encouraged for the physicians in the palliative care of terminally ill patients in an emergency room.

Keywords: communication skills, terminally ill, do-not-resuscitate, DNR, emergency room, ER, SHARE model

\section{Introduction}

Patients who are taken to the emergency room (ER) for the end-stage of their illness are often in a grave condition. There is currently an increasing emphasis on the issue of patient autonomy and dying with dignity and more end-of-life care is being initiated in ERs. ${ }^{1-4}$ In these cases, caring physicians may raise concerns about care 
aggressiveness and sometimes provide a palliative approach to avoid the unnecessary suffering of these the patients. ${ }^{1-4}$ As instruction to all the involved healthcare providers not to perform further interventions and procedures, the signing of do-not-resuscitate (DNR) consent by the physicians in conjunction with the patients or their proxy decision makers is required $^{5,6}$ and early initiation of DNR discussions is suggested to improve end-of-life care. ${ }^{2}$ On the other hand, many ethnical Chinese believe that life and death are predetermined and that an individual must not plan for or discuss concerns related to end-of-life care. ${ }^{7}$ Most families may choose life-sustaining therapy to prolong the life of the patient or family member because of filial piety, particularly when the patient is a parent or other family elder. ${ }^{8}$ In addition, some family members may concern about a decrease in potentially critical interventions and survival rate of the patients once early DNR orders were signed. ${ }^{6,9}$ Therefore, physicians play an extremely important role not only in determining the need for hospice and palliative care for the patients, but also in notifying patients and their family members of the terminal condition of the patients. ${ }^{1,2}$

Information concerning a patient's condition from the physician is vital to family members' decision making concerning the signing of DNR consent. In that moment, family members are typically extremely anxious or emotional and may find it difficult to make an optimal medical decision on behalf of the patient. ${ }^{2}$ In the absence of a bad news communication model and assessment tools, the signing rate of DNR consent is only $23 \% .{ }^{10}$ Therefore, a high level of communication skills is required in the caring physician to establish effective patient condition notification. ${ }^{11,12}$ Among difference communication models, the SHARE model was developed by the Japan PsychoOncology Society ${ }^{13,14}$ to understand patients' preferences regarding the disclosure of bad news and it emphasizes effective communication to provide patients with psychological support when receiving bad news. ${ }^{15}$ The acronym SHARE represents the four main components of this structured model: Supportive environment, How to deliver the bad news, Additional information, Reassurance, and Emotional support. ${ }^{13}$ The detailed emotional support training provided by the SHARE model has proven to have a positive effect in the areas of notification skills, emotional support, and providing information. ${ }^{16}$ Based on studies related to cancer patients' preference for being told the truth, the SHARE communication model has provided an emotional cushion to help patients cope during their time of grief $^{15}$ and to promote communication among patients, family members, and physicians. ${ }^{12,17}$ These programs are led by certified facilitators using small classes-four participants, two facilitators, and one standard patient — and role play to enable participants to learn important communication skills. ${ }^{15}$ After participating in the SHARE course of communication skills training, healthcare personnel's preference for truth-telling improve significantly. ${ }^{12,15,18}$ In this study, we aimed to investigate the association between the communication skills of the physicians who had participated in the SHARE model course on patient notification and the signing of DNR consent by the terminally ill patients at ERs.

\section{Methods \\ Ethical Statement}

The Chang Gung Memorial Hospital institutional review board approved this study (approval number 201700429B0). Approach to the patients' medical records was allowed by this approved number. The researchers explained the goals of the project in detail to the subjects before obtaining their consent and all the patients involved in the study did provide written consent. The patient privacy protection was performed using anonymous code for a patient's identity. The research data was kept confidential and only used for the purposes of the study and conducted in accordance with the Declaration of Helsinki.

\section{Study Setting and study Population}

This was a cross-sectional study and the work has been reported with the (Strengthening the Reporting of Cohort Studies in Surgery) STROCSS criteria. ${ }^{19}$ This study was performed in the ER of a 2686-bed medical center in southern Taiwan. ${ }^{20-22}$ The research population consisted of end-stage terminally ill patients with cancer or other terminal diseases (such as cardiomyopathy, congestive heart failure, chronic obstructive pulmonary disease, emphysema, heart disease, liver disease ...etc.) who visited the ER and had received a recommendation of signing a DNR. The exclusion criteria consisted of the following: patients who had already signed DNR consent, patients aged under 20 years of age, patients who had received surgery or had committed suicide, patients not strong enough to complete the questionnaire survey, patients who would be discharged within $24 \mathrm{hrs}$, and patients who could not communicate well in Chinese or Taiwanese. This study included 19 attending physicians in the emergency department who had attended SHARE 
model-centered communication skills training programs. Any potential study subject was enrolled during the study period from May 1, 2017 to April 30, 2018 when the both attending physician and the observer were on duty in the emergency room, but only the study subject who had signed the consent form was recruited into the study. The DNR consent was signed by both the patient and his (her) surrogate. If the patient was unable to sign the consent (for example, conscious disturbance or critical weakness), then the consent would be signed by the surrogates.

\section{Assessment of Communication Skills}

Before the implementation of the research, two nurse practitioners-with at least 20 years of experience in emergency care work, and that were members of the medical team-were assigned as "observers". These two nurse practitioners had attended the SHARE course model and were familiar with communication skills in the training program. The observers received observation training to reduce bias and to obtain an objective assessment. The procedures for observing physicians' presentation of bad news began with an explanation of the study's goals and implementation steps. After the physicians gave their consent, the observers assessed the performance of those attending physicians who had agreed to participate in the study. To quantify the communication skills of the physicians in the process of explaining a signing of DNR consent to the family member, observation forms (i.e., the patient condition notification scoring form) were used by the observers to score the physicians' presentation of bad news. The observation form was designed based on the SHARE model and included four aspects: supportive environment, how to communicate bad news, provision of additional information, reassurance, and emotional support. ${ }^{12}$ Each question had three possible responses: "I have not done it," "I have partially done it," and "I have done it fully," which were scored with 0,1 , and 2 points respectively. The overall questionnaire score was the sum of the scores for each question, and possible total scores ranged from 0 to 34 points. Higher scores indicated that there was a greater fit of the SHARE model in the patient condition notification.

\section{Data Collection}

In addition to the observation form, the research data included the following: (1) The patient medical records, including age, gender, marital status, number of chronic diseases, triage level, Charlson Comorbidity Index (CCI) -which relies on the International Classification of Disease 9th Clinical Modification to assign scores to patient illnesses ${ }^{23}$ - the Glasgow Coma Scale (GCS), acute complications, and the patient's source of medical expenses in multiple-choice; and (2) The questionnaire survey completed by family member interviews, including age, gender, level of education, relationship with the patient, religious belief, related situational experience of signing DNR consent (multiple choice), and reasons for considering signing DNR consent (multiple choice). The interviews of family members were conducted with the patients' closest available living blood relatives. For privacy, face-to-face interviews were conducted in quiet, undisturbed areas in the ER.

\section{Statistical Analysis}

A statistical analysis was performed using SPSS software (version 23.0, IBM Corp., Armonk, NY, USA). ChiSquared test were used to compare categorical data. The odds ratios (ORs) with $95 \%$ confidence intervals (CIs) of the associated conditions of the patients were obtained. The continuous variables were analyzed using one-way analysis of variance with a Games-Howell post-hoc test, and expressed as mean \pm standard deviation (SD). A multivariate logistic regression model was applied to identify independent significant factors of the patient and family member variables (source of medical expenses: $1=$ Yes, $0=$ No; discussed DNR with the patient: $1=$ Yes, $0=$ No; discussed DNR with the physician: $1=$ Yes, $0=$ No; experienced signing a DNR order for another family member: $1=$ Yes, $0=$ No; physician's initiative in discussing with families: $1=$ Yes, $0=$ No; receiving notice of the patient's critical condition: $1=$ Yes, $0=$ No; patient's own intention: 1 = Yes, $0=$ No; discussion among the patient's family members: $1=$ Yes, $0=$ No; predicting limited life expectancy: 1 = Yes, $0=$ No) as well as the four main components of the observation form (supportive environment: $0=$ "I have not done it", 1 = "I have partially done it", 2 = "I have done it fully"; how to deliver the bad news: $0=$ "I have not done it", 1 = "I have partially done it", 2 = "I have done it fully"; additional information: $0=$ "I have not done it", 1 = "I have partially done it", 2 = "I have done it fully"; reassurance and emotional support: $0=$ "I have not done it", 1 = "I have partially done it", 2 = "I have done it fully") on the signing of DNR consent. $p$ values $<0.05$ were defined as statistically significant. 


\section{Results}

\section{Characteristics of the Patients}

In total, there were 109 patients enrolled into this study, with 70 patients having signed a DNR and 39 not. As shown in Table 1, there were no significant differences in patient characteristics regarding the age, gender, marital status, triage level, number of chronic diseases, CCI, GCS, acute complications, and mortality between those who had signed (S-DNR) and those who had not signed DNR consent (N-DNR). A significant difference was observed in the coverage of medical care expenses. There was a significantly lower rate of insurance paying for patients' medical expenses in S-DNR consent than N-DNR (18.6\% vs $56.4 \% ; \mathrm{p}<0.001)$.

\section{Characteristics of the Family Members}

As shown in Table 2, there were no significant differences in characteristics of the family members regarding the age, gender, level of education, relationship with the patient, and religious belief between those family members who had signed or did not sign DNR consent. The S-DNR had a higher rate of signing DNR than N-DNR when they had discussed DNR with the patients $(45.7 \%$ vs $12.8 \%, \mathrm{p}<0.001)$ or with physicians $(54.3 \%$ vs $17.9 \%, \mathrm{p}<0.001)$, or had experienced signing DNR for another family member $(17.1 \%$ vs $0.0 \%, p=0.015)$. Regarding the reasons for considering signing DNR consent, there were significantly lower rates of "physician initiated the discussion with family members," "receiving notice of the patient's critical condition," "discussion among the patient's family members," and "a limited life expectancy is predicted" but a higher rate of "patient's own intention" in those who signed DNR consent compared to those that had not.

\section{Assessment of Communication Skills}

Regarding the four main factors of the SHARE model (Table 3), an analysis of the observation form revealed that S-DNR had a higher score for "supportive environment" $(6.07 \pm 1.64$ vs $4.90 \pm 1.87 ; p=0.001)$, "how to deliver the bad news" (13.49 \pm 0.78 vs $12.62 \pm 1.14$; $\mathrm{p}<0.001$ ), and "reassurance and emotional support" $(4.96 \pm 1.41$ vs $3.23 \pm 1.49 ; \mathrm{p}<0.001)$ than N-DNR. There was no significant difference in the score for "additional information" between S-DNR and N-DNR. Compared to N-DNR, the S-DNR had a higher score for
Table I Patient Characteristic in Those Who Had Signed (S-DNR) or Did Not Sign a DNR Consent (N-DNR)

\begin{tabular}{|c|c|c|c|}
\hline Variables & $\begin{array}{l}\text { N-DNR (n } \\
=39)\end{array}$ & $\begin{array}{l}\text { S-DNR (n } \\
=70)\end{array}$ & $p$ value \\
\hline Age (years), mean $\pm S D$ & $78.5 \pm 12.6$ & $74.3 \pm 13.8$ & $0.126^{\dagger}$ \\
\hline $\begin{array}{l}\text { Gender, n (\%) } \\
\text { Female } \\
\text { Male }\end{array}$ & $\begin{array}{l}12(30.8) \\
27(69.2)\end{array}$ & $\begin{array}{l}31(44.3) \\
39(55.7)\end{array}$ & $0.238^{*}$ \\
\hline $\begin{array}{l}\text { Marital status, } \mathrm{n}(\%) \\
\text { Married } \\
\text { Single, widowed or } \\
\text { divorced }\end{array}$ & $\begin{array}{l}15(38.5) \\
24(61.5)\end{array}$ & $\begin{array}{l}40(57.1) \\
30(42.9)\end{array}$ & $0.06 I^{*}$ \\
\hline $\begin{array}{l}\text { Triage level, n (\%) } \\
\text { Level I } \\
\text { Level II } \\
\text { Level III or IV }\end{array}$ & $\begin{array}{l}16(41.0) \\
18(46.2) \\
5(12.8)\end{array}$ & $\begin{array}{l}28(40.0) \\
27(38.6) \\
15(21.4)\end{array}$ & $0.505^{*}$ \\
\hline $\begin{array}{l}\text { Number of chronic } \\
\text { diseases, } n \text { (\%) } \\
\text { One } \\
\text { Two } \\
\geq \text { Three }\end{array}$ & $\begin{array}{l}6(15.4) \\
18(46.2) \\
15(38.4)\end{array}$ & $\begin{array}{l}19(27.1) \\
24(34.3) \\
27(38.3)\end{array}$ & $0.297 *$ \\
\hline $\mathrm{CCl}$, mean $\pm \mathrm{SD}$ & $3.10 \pm 2.01$ & $2.99 \pm 1.85$ & $0.760^{\dagger}$ \\
\hline $\mathrm{GCS}$, mean $\pm \mathrm{SD}$ & $6.87 \pm 3.11$ & $6.99 \pm 3.38$ & $0.862^{\dagger}$ \\
\hline Acute complications, n (\%) & $35(89.7)$ & $52(74.3)$ & $0.093 *$ \\
\hline \multicolumn{4}{|l|}{$\begin{array}{l}\text { Source of medical } \\
\text { expenses, } n(\%)\end{array}$} \\
\hline Self savings & $13(33.3)$ & $19(27.1)$ & $0.645^{*}$ \\
\hline Pay by spouse & $8(20.5)$ & $9(12.9)$ & $0.435^{*}$ \\
\hline Sharing by children & $31(79.5)$ & $52(74.3)$ & $0.707^{*}$ \\
\hline Pay by insurance & $22(56.4)$ & $13(18.6)$ & $<0.00 I^{*}$ \\
\hline Mortality, n (\%) & $18(46.2)$ & $40(57.1)$ & $0.367^{*}$ \\
\hline
\end{tabular}

Notes: Statistical analysis: ${ }^{*}$ Chi-Squared test, ${ }^{\dagger}$ unpaired Student t-test. Abbreviations: $\mathrm{CCl}$, Charlson Comorbidity Index; DNR, do-not-resuscitate; GCS, Glasgow Coma Scale; SD, standard deviation.

the following questions: "relationship with the patient" and "invite family members to understand the condition" in the component of supportive environment; "avoid technical terms," "possible causes of cardiac arrest," and "if the condition is not explained smoothly, is there a request for assistance" in the component of how to deliver the bad news; "explain the future treatment policy" in the component of additional information; and "comfort patients and encourage their families to think positively" and "expressing concern" in the component of reassurance and emotional support. However, the score for "express the same mood' is lower in S-DNR than N-DNR. 
Table 2 Characteristic of Family Members in Those Who Had Signed (S-DNR) or Did Not Sign a DNR Consent (N-DNR)

\begin{tabular}{|c|c|c|c|}
\hline Variables & $N-D N R(n=39)$ & S-DNR (n = 70) & $p$ value \\
\hline Age (years) & $51.1 \pm 13.4$ & $52.7 \pm 11.5$ & $0.518^{\dagger}$ \\
\hline Gender, n (\%) & & & $0.238^{*}$ \\
\hline Female & $17(43.6)$ & $38(54.3)$ & \\
\hline Male & $22(56.4)$ & $32(45.7)$ & \\
\hline Level of education, $n(\%)$ & & & $0.316^{*}$ \\
\hline Junior high school or below & $9(23.1)$ & $21(30.0)$ & \\
\hline Senior high school (or technical education) & $15(38.5)$ & $25(35.7)$ & \\
\hline Junior college & II (28.2) & II (I5.7) & \\
\hline University or above & $4(10.3)$ & $13(18.6)$ & \\
\hline Relationship with the patient, $\mathrm{n}(\%)$ & & & $0.307^{*}$ \\
\hline Spouse & $5(12.8)$ & I3 (18.6) & \\
\hline Son & $20(51.3)$ & $27(38.6)$ & \\
\hline Daughter & II (28.2) & $17(24.3)$ & \\
\hline Other & $3(7.7)$ & $13(18.5)$ & \\
\hline Religious belief, n (\%) & & & $0.140^{*}$ \\
\hline Buddhism & $5(12.8)$ & $20(28.6)$ & \\
\hline Taoism & $24(6 \mid .5)$ & $32(45.7)$ & \\
\hline Other (including none) & $10(25.6)$ & $18(25.7)$ & \\
\hline \multicolumn{4}{|l|}{ Situation in signing DNR, n (\%) } \\
\hline Discussed DNR with the patient & $5(12.8)$ & $32(45.7)$ & $0.00 I^{*}$ \\
\hline Discussed DNR with the physician & $7(17.9)$ & $38(54.3)$ & $<0.00 I^{*}$ \\
\hline Experienced signing DNR for another family member, $\mathrm{n}$ (\%) & $0(0.0)$ & $12(17.1)$ & $0.015^{*}$ \\
\hline \multicolumn{4}{|l|}{ Reasons for considering signing DNR upon, $\mathrm{n}(\%)$} \\
\hline Physician initiated the discussion with family members & $29(74.4)$ & $7(10.0)$ & $<0.001 *$ \\
\hline Receiving notice of the patient's critical condition & $31(79.5)$ & $30(42.9)$ & $<0.001 *$ \\
\hline Patient's own intention & $4(10.3)$ & $28(40.0)$ & $0.002^{*}$ \\
\hline Discussion among the patient's family members & $27(69.2)$ & $31(44.3)$ & $0.021 *$ \\
\hline Predicting that the patient cannot be cured & $17(43.6)$ & $26(37.1)$ & $0.649 *$ \\
\hline Patient has been in and out of the hospital frequently & $5(12.8)$ & $10(14.3)$ & $0.891 *$ \\
\hline A limited life expectancy is predicted & $15(38.5)$ & $12(17.1)$ & $0.025 *$ \\
\hline
\end{tabular}

Notes: Statistical analysis: ${ }^{*}$ Chi-Squared test, ${ }^{\dagger}$ unpaired Student t-test. Age is expressed as mean \pm standard deviation. Abbreviation: DNR, do-not-resuscitate.

\section{Independent Significant Factors for Signing DNR Consent}

A multivariate logistic regression model (Table 4) was applied to identify the independent significant factors of the patient characteristics and family member characteristics that contributing to the signing of a DNR consent in the Tables 1 and 2, respectively, as well as the four main components of the observation form in the Table 3. The analysis revealed that "how to deliver the bad news" and "reassurance and emotional support" were positive independent significant factors but that "physician initiated the discussion with family members" and "a limited life expectancy is predicted" were negative independent significant factors for signing DNR consent.

\section{Discussion}

This study investigated the association between signing of DNR consent by terminally ill patients and the communication skill of the ER physicians who had participated in the SHARE model course on patient notification. The findings revealed that knowing how to convey bad news and providing reassurance and emotional support were significantly correlated with a higher rate of signing DNR consent in terminally ill patients. Existing studies have reported that what physicians fear most is to face 
Table 3 Scores from the Observation Form Which Contained the Four Main Factors of the SHARE Model

\begin{tabular}{|c|c|c|c|}
\hline Variables & N-DNR $(n=39)$ & $\begin{array}{l}\text { S-DNR } \\
(n=70)\end{array}$ & $p$ value \\
\hline Supportive environment & $4.90 \pm 1.87$ & $6.07 \pm 1.64$ & 0.001 \\
\hline Self-introduction & $2.23 \pm 0.71$ & $2.11 \pm 0.81$ & 0.453 \\
\hline Choose a quiet environment & $1.18 \pm 0.64$ & $1.23 \pm 0.80$ & 0.744 \\
\hline Relationship with the patient & $0.85 \pm 0.67$ & $1.29 \pm 0.66$ & 0.001 \\
\hline Invite family members to understand the condition & $1.49 \pm 0.68$ & $1.74 \pm 0.53$ & 0.032 \\
\hline How to deliver the bad news & $12.62 \pm 1.14$ & $13.49 \pm 0.78$ & $<0.001$ \\
\hline Avoid technical terms & $1.38 \pm 0.54$ & $1.81 \pm 0.39$ & $<0.001$ \\
\hline The whole process of the disease & $1.77 \pm 0.43$ & $1.90 \pm 0.35$ & 0.086 \\
\hline Changes in related emergency procedures & $1.85 \pm 0.37$ & $1.94 \pm 0.29$ & 0.131 \\
\hline Possible causes of cardiac arrest & $1.85 \pm 0.43$ & $2.00 \pm 0.00$ & 0.003 \\
\hline Expressing the role of medical care at the time & $1.92 \pm 0.27$ & $1.97 \pm 0.17$ & 0.251 \\
\hline Confirmation of family members' understanding of the relevant condition & $1.90 \pm 0.31$ & $1.89 \pm 0.32$ & 0.853 \\
\hline If the condition is not explained smoothly, is there a request for assistance & $1.62 \pm 0.49$ & $1.91 \pm 0.28$ & $<0.001$ \\
\hline Additional information & $5.13 \pm 0.92$ & $4.99 \pm 0.92$ & 0.442 \\
\hline Understand the patient's wishes and confirm it & $1.72 \pm 0.51$ & $1.87 \pm 0.38$ & 0.077 \\
\hline Explain the future treatment policy & $1.41 \pm 0.68$ & $1.77 \pm 0.52$ & 0.002 \\
\hline Provide other medical information & $1.90 \pm 0.38$ & $|.7| \pm 0.5 \mathrm{I}$ & 0.055 \\
\hline Reassurance and Emotional support & $3.23 \pm 1.49$ & $4.96 \pm 1.41$ & $<0.001$ \\
\hline Express the same mood & $1.82 \pm 0.39$ & $1.50 \pm 0.61$ & 0.004 \\
\hline Encourage comfort patients and their families to think positively & $1.28 \pm 0.72$ & $1.81 \pm 0.43$ & $<0.001$ \\
\hline Expressing concern & $1.03 \pm 0.49$ & $1.59 \pm 0.69$ & $<0.001$ \\
\hline
\end{tabular}

Notes: All values are calculated by the unpaired Student's $t$-test and expressed as mean \pm SD.

Abbreviation: DNR, do-not-resuscitate.

patients and their family members alone, especially when conveying information in situations that are not covered in textbooks. ${ }^{11}$ To cope with such situations, physicians should learn how to deal with pressure, enhance their self-confidence, and rely on observation of their peers and the use of frameworks to enhance their ability to perform patient condition notification. ${ }^{11}$ Physicians should therefore pay close attention to their words, observe their peers' explanations, and rely on selfreflection to improve their communication skills. ${ }^{11,24}$ Furthermore, the last dimension (reassurance and emotional support) should be emphasized throughout the

Table 4 Multivariate Logistic Regression Model for the Identification of the Significant Factors for Signing a DNR Consent

\begin{tabular}{|c|c|c|c|c|}
\hline Predictors & $\boldsymbol{\beta}$ & OR & $95 \% \mathrm{Cl}$ & $p$ value \\
\hline Intercept & -9.50 & & & \\
\hline Medical expenses pay by insurance & -0.20 & 0.82 & $0.22-3.12$ & 0.766 \\
\hline Discussed DNR with the patient & -1.19 & 0.30 & $0.03-2.96$ & 0.305 \\
\hline Discussed DNR with the physician & 1.01 & 2.73 & $0.69-10.8$ & 0.152 \\
\hline Experienced signing DNR consent for another family member & 0.50 & 1.65 & $0.25-11.05$ & 0.607 \\
\hline Physician initiated the discussion with family members & -2.93 & 0.05 & $0.01-0.32$ & 0.001 \\
\hline Receiving notice of the patient's critical condition & 0.14 & 1.15 & $0.28-4.69$ & 0.847 \\
\hline Patient's own intention & 0.89 & 2.43 & $0.32-20.02$ & 0.409 \\
\hline Discussion among the patient's family members & -0.11 & 0.90 & $0.26-3.14$ & 0.869 \\
\hline A limited life expectancy is predicted & -1.50 & 0.22 & $0.07-0.72$ & 0.012 \\
\hline Supportive environment & -0.01 & 1.00 & $0.68-1.47$ & 0.981 \\
\hline How to deliver the bad news & 0.57 & 1.78 & $1.02-3.09$ & 0.042 \\
\hline Additional information & 0.30 & 1.34 & $0.64-2.81$ & 0.432 \\
\hline Reassurance and emotional support & 0.57 & 1.77 & $1.12-2.83$ & 0.014 \\
\hline
\end{tabular}

Abbreviations: DNR, do-not-resuscitate; $\mathrm{OR}$, odds ratio; $\mathrm{Cl}$, confidential interval. 
SHARE model-centered truth-telling process to reflect the preferences of patients with cancer. ${ }^{13,14}$

The results of this study showed no significant differences in patient characteristics concerning the signing of a DNR, with the exception of a significantly lower rate of insurance paying for patients' medical expenses in S-DNR than N-DNR. These results are contradictory to earlier results reported in Taiwan, which state that patients' functional status, disease severity, and days of hospitalization are significant predictive factors for clinical physicians' and family members' DNR decisions. ${ }^{2,25,26}$ We believe that this contradiction can be attributed to that study being performed on different patient population, as opposed to this study, in which only end-stage patients with cancer or other terminal diseases were included.

A higher rate of "patient's own intention" in S-DNR than N-DNR was observed in this study. Obviously, if a patient is able to clearly convey his or her treatment wishes before becoming terminally ill, it would lessen family members' decision-making anxiety and sense of guilt. ${ }^{27}$ Nonetheless, the family members play a key role in the decision making process of signing DNR consent. Family members' acceptance of the patient's wishes for DNR consent had a positive effect on DNR signing. ${ }^{28,29}$ Studies from Taiwan have reported that all decisions for older people-from living in long-term care facilities to receiving life-sustaining therapy or signing DNR consent - were made by their families. ${ }^{30,31}$ However, approximately half of the families thought that this decision should be made by the patients themselves and wanted to know what their parents thought of the decision making but still preferred that the healthcare provider ask them. ${ }^{32}$ This also reflects the importance of physicians' communication skills in such circumstances. Different explanatory approaches are necessary at different stages of a disease when performing patient condition notification while using the essential aspects of the SHARE model in a flexible manner in accordance with patient needs. Patients, family members, and the medical team jointly participating in a more objective and multifaceted assessment will result in a more accurate portrayal of patient condition notification skills required by emergency physicians. ${ }^{12,33}$

In this study, the multivariate logistic regression model also confirmed "physician initiated the discussion with family members" as a significantly negative independent factor for signing DNR consent. We believe that the reason for this may be that if a patient's family members consistently evade discussion of the subject of death, believe that DNR signing implies giving up treatment, or believe that the time of DNR signing has not arrived, such family members will generally avoid actively mentioning DNR consent, preferring to wait passively for the physician's decision. Such family members typically cannot reach a consensus concerning medical action when they are confronted with an emergency health crisis, making it difficult to obtain DNR consent. ${ }^{27,34,35}$ Furthermore, in this study, a patient's shortened life expectancy is negatively correlated with DNR signing by family members. Whether it means that a longer life expectancy is associated with a heavier burden for the family members require further investigation. However, we can infer from the results of this study that it is important for physicians to take the above two points into consideration when providing patient condition notification.

This study has some limitations. First, the sample size is limited. Second, this study was limited to one medical center and the results may not be generalizable to other medical centers. Third, the attitude of the physicians involved in this study toward the end-of-life care may vary and as such, may lead to bias, even though they had all attended the SHARE course. Fourth, this study included end-stage patients with cancer or other diseases; however, the patient's will or condition to sign DNR consent may differ in those who had cancer and those who had not, which may also lead to bias. Lastly, according to the recruiting procedure of the study subjects, there may be some selection bias in the study, seeing that only 19 of more than 40 attending physicians in the emergency department had attended in the study and the total terminally ill patients screened during this study period was unknown.

\section{Conclusion}

This study revealed that knowledge of how to convey bad news and provide reassurance and emotional support in ER physicians who had attended the SHARE model course were significantly correlated with a higher rate of signing DNR consent among terminal patients. The learning of such skill from attendance of SHARE model course is encouraged for the physicians in the palliative care of terminally ill patients in an emergency room.

\section{Disclosure}

The authors report no conflicts of interest in this work.

\section{References}

1. Brizzi M, Abul-Kasim K, Jalakas M, Selariu E, Pessah-Rasmussen H, Zia E. Early do-not-resuscitate orders in intracerebral haemorrhage; frequency and predictive value for death and functional outcome. A retrospective cohort study. Scand J Trauma Resusc Emerg Med. 2012;20:36. doi:10.1186/1757-7241-20-36 
2. Cheng YH, Wang JJ, Wu KH, Huang S, Kuo ML, Su CH. Do-notresuscitate orders and related factors among family surrogates of patients in the emergency department. Supp Care Cancer. 2016;24:1999-2006. doi:10.1007/s00520-015-2971-7

3. Vancini-Campanharo CR, Vancini RL, Machado Netto MC, et al. Do not attempt resuscitation orders at the emergency department of a teaching hospital. Einstein (Sao Paulo). 2017;15:409-414. doi:10.1590/s167945082017 ao3999

4. Cruz-Carreras MT, Chaftari P, Viets-Upchurch J. Advance care planning: challenges at the emergency department of a cancer care center. Supp Care Cancer. 2018;26:585-588. doi:10.1007/s00520017-3870-x

5. Bradford MA, Lindenauer PK, Wiener RS, Walkey AJ. Do-notresuscitate status and observational comparative effectiveness research in patients with septic shock*. Crit Care Med. 2014;42:2042-2047. doi:10.1097/ccm.0000000000000403

6. Richardson DK, Zive D, Daya M, Newgard CD. The impact of early do not resuscitate (DNR) orders on patient care and outcomes following resuscitation from out of hospital cardiac arrest. Resuscitation. 2013;84:483-487. doi:10.1016/j.resuscitation.2012.08.327

7. Ferrans Y-FHC. Recognizing Chinese Americans' cultural needs in making end-of-life treatment decisions. J Hospice Palliative Nurs. 2007;9:132-140. doi:10.1097/01.NJH.0000269993.13625.49

8. Lo YT, Wang JJ, Liu LF, Wang CN. Prevalence and related factors of do-not-resuscitate directives among nursing home residents in Taiwan. J Am Med Dir Assoc. 2010;11:436-442. doi:10.1016/j. jamda.2009.10.006

9. Sarkari NN, Perman SM, Ginde AA. Impact of early do-not-attemptresuscitation orders on procedures and outcomes of severe sepsis. J Crit Care. 2016;36:134-139. doi:10.1016/j.jcrc.2016.06.030

10. Tsai SL, C. S, Zheng MJ, Ho MJ. Special report on a faculty development workshop on clinical communication. $J$ Med Educ. 2011;15:191-198.

11. Hsieh M, Hsu CW. The strategies of doctor-patient communication in the emergency department. Taipei City Med J. 2014;11:121-128.

12. Cheng $\mathrm{YH}$, Chen $\mathrm{CH}$, Chen FJ, et al. The training in SHARE communication course by physicians increases the signing of do-notresuscitate orders for critical patients in the emergency room (cross-sectional study). Int J Surg. 2019;68:20-26. doi:10.1016/j. ijsu.2019.06.005

13. Fujimori M, Akechi T, Morita T, et al. Preferences of cancer patients regarding the disclosure of bad news. Psychooncology. 2007;16:573-581. doi:10.1002/pon.1093

14. Fujimori M, Parker PA, Akechi T, Sakano Y, Baile WF, Uchitomi Y. Japanese cancer patients' communication style preferences when receiving bad news. Psychooncology. 2007;16:617-625. doi:10.1002/pon.1102

15. Tang WR, Chen KY, Hsu SH, et al. Effectiveness of Japanese SHARE model in improving Taiwanese healthcare personnel's preference for cancer truth telling. Psychooncology. 2014;23:259-265. doi: $10.1002 /$ pon. 3413

16. Tang WR, Chen GY, Hsu SH, Fang JK. Preliminary effects of truth-telling training. $J$ Cancer Res Pract. 2010;26:112-124. doi:10.6323/JoCRP.2010.26.3.3

17. Fujimori M, Akechi T, Akizuki N, et al. Good communication with patients receiving bad news about cancer in Japan. Psycho-Oncology. 2005;14:1043-1051. doi:10.1002/pon.917

18. Wadagni AC, Barogui YT, Johnson RC, et al. Delayed versus standard assessment for excision surgery in patients with Buruli ulcer in Benin: a randomised controlled trial. Lancet Infect Dis. 2018;18:650-656. doi:10.1016/s1473-3099(18)30160-9
19. Agha RA, Borrelli MR, Vella-Baldacchino M, Thavayogan R, Orgill DP. The STROCSS statement: strengthening the reporting of cohort studies in surgery. Int J Surg. 2017;46:198-202. doi:10.1016/j. ijsu.2017.08.586

20. Hsieh CH, Hsu SY, Hsieh HY, Chen YC. Differences between the sexes in motorcycle-related injuries and fatalities at a Taiwanese level I trauma center. Biomed J. 2017;40:113-120. doi:10.1016/j.bj.2016.10.005

21. Hsieh CH, Liu HT, Hsu SY, Hsieh HY, Chen YC. Motorcycle-related hospitalizations of the elderly. Biomed J. 2017;40:121-128. doi:10.1016/j.bj.2016.10.006

22. Hsieh CH, Chen YC, Hsu SY, Hsieh HY, Chien PC. Defining polytrauma by abbreviated injury scale $>/=3$ for a least two body regions is insufficient in terms of short-term outcome: a cross-sectional study at a level I trauma center. Biomed J. 2018;41:321-327. doi:10.1016/j. bj.2018.08.007

23. Stavem K, Hoel H, Skjaker SA, Haagensen R. Charlson comorbidity index derived from chart review or administrative data: agreement and prediction of mortality in intensive care patients. Clin Epidemiol. 2017;9:311-320. doi:10.2147/clep.S133624

24. Yang LY, Yang YY, Huang CC, et al. Simulation-based inter-professional education to improve attitudes towards collaborative practice: a prospective comparative pilot study in a Chinese medical centre. BMJ Open. 2017;7:e015105. doi:10.1136/bmjopen2016-015105

25. Fu P, Lin WY, Chao KP, Chiu HW, Chen CH, Huang SJ. The epidemiology of do-not-resuscitate orders in the emergency department of Taipei City hospital. Taipei City Med J. 2016;13:48-52.

26. Chang L, Huang SJ, Hsiao SH. From ICU return to end-of-life care plan. Taipei City Med J. 2015;12:13-27.

27. Huang L, Wei SE. End of life medical decision-making in intensive care unit: an analysis for Do-Not-Resuscitate (DNR) designation. Journal of Life Education. 2013;5:25-56.

28. Quest TE, Asplin BR, Cairns CB, Hwang U, Pines JM. Research priorities for palliative and end-of-life care in the emergency setting. Acad Emerg Med. 2011;18:e70-76. doi:10.1111/j.1553-2712.2011. 01088.x

29. Chang DW, Brass EP. Patient and hospital-level characteristics associated with the use of Do-Not-Resuscitate orders in patients hospitalized for sepsis. J Gen Intern Med. 2014;29:1256-1262. doi:10.1007/ s11606-014-2906-x

30. Fang YC, Pai MC, Wang LC, et al. Factors influencing family surrogates' intention with regard to Do-Not-Resuscitate directive for patients with dementia. Clin Gerontol. 2018;1-9. doi:10.1080/ 07317115.2018.1461164

31. Chang HT, Lin MH, Chen CK, Chou P, Chen TJ, Hwang SJ. Trends of Do-Not-Resuscitate consent and hospice care utilization among noncancer decedents in a tertiary hospital in Taiwan between 2010 and 2014: a Hospital-based observational study. Medicine (Baltimore). 2016;95:e5394. doi:10.1097/md.0000000000005394

32. Chen TR, H. W, Chiu TY, Yeh SL. The intention of families toward withholding life-sustaining treatment for patients with COPD in end-of-life. Taiwan J Hosp Palliat Care. 2014;19:138-154.

33. Shoenberger JM, Yeghiazarian S, Rios C, Henderson SO. Death notification in the emergency department: survivors and physicians. West J Emerg Med. 2013;14:181-185. doi:10.5811/westjem.2012.10.14193

34. Santonocito C, Ristagno G, Gullo A, Weil MH. Do-not-resuscitate order: a view throughout the world. J Crit Care. 2013;28:14-21. doi:10.1016/j.jcrc.2012.07.005

35. Yang F, Lee SJ, Wang JY, Yang SK, Lin SY, Chen CH. The factors influencing the behavior intention of Do-Not-Resuscitate requests for families. Cheng Ching Med J. 2015;12:30-39. 


\section{Publish your work in this journal}

Risk Management and Healthcare Policy is an international, peerreviewed, open access journal focusing on all aspects of public health, policy, and preventative measures to promote good health and improve morbidity and mortality in the population. The journal welcomes submitted papers covering original research, basic science, clinical \& epidemiological studies, reviews and evaluations, guidelines, expert opinion and commentary, case reports and extended reports. The manuscript management system is completely online and includes a very quick and fair peer-review system, which is all easy to use. Visit http://www.dovepress.com/testimonials.php to read real quotes from published authors.

Submit your manuscript here: https://www.dovepress.com/risk-management-and-healthcare-policy-journal 